Document downloaded from:

http://hdl.handle.net/10251/178221

This paper must be cited as:

Rojas, J.; Higuera-Trujillo, JL.; Muniz, G.; Marín-Morales, J. (2021). Product Validation in Creative Processes: A Gender Perspective in Industrial Design Projects. IEEE. 760-765. https://doi.org/10.1109/EDUCON46332.2021.9453948

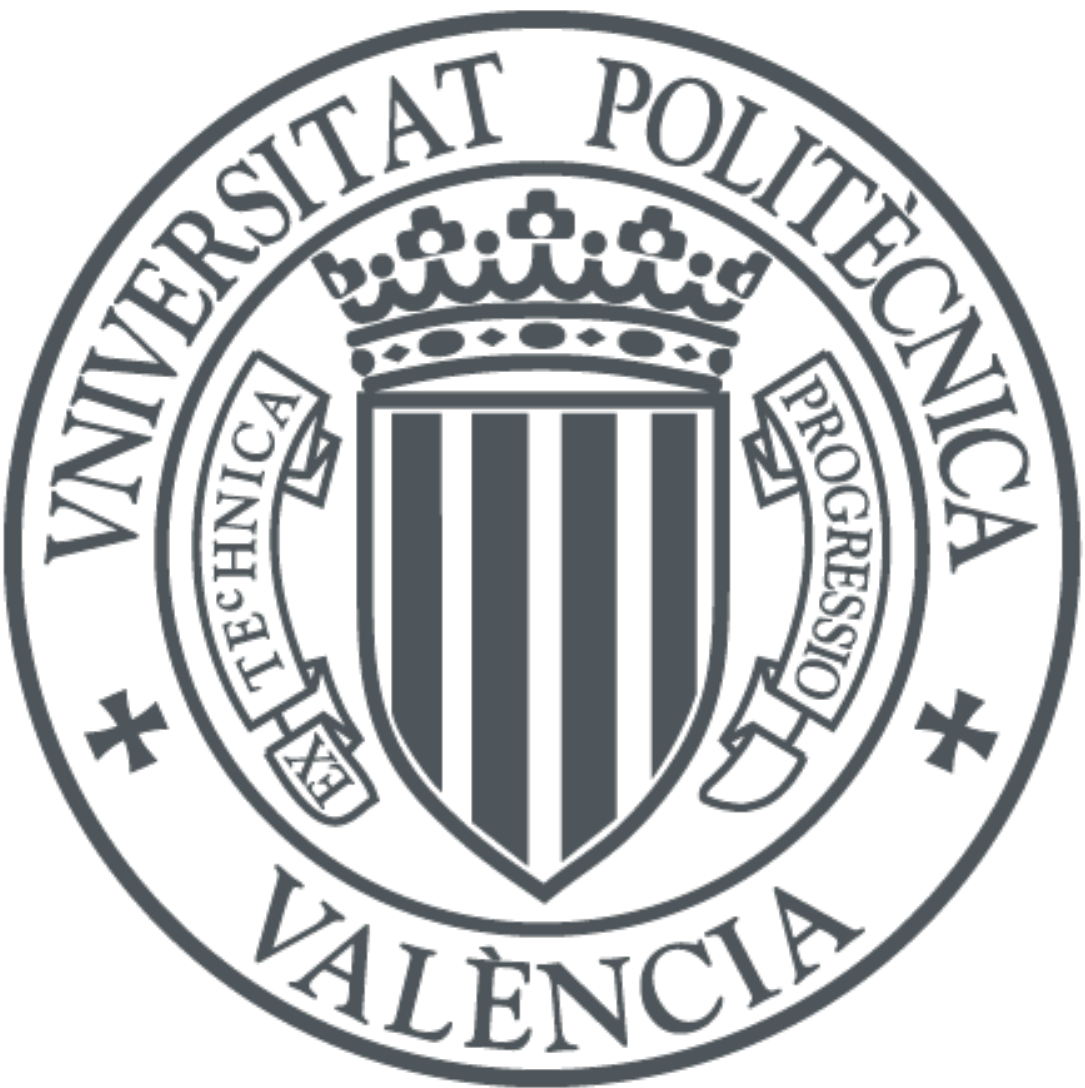

The final publication is available at

https://doi.org/10.1109/EDUCON46332.2021.9453948

Copyright IEEE

Additional Information 


\title{
Product Validation in Creative Processes: A Gender Perspective in Industrial Design Projects
}

\author{
Juan-Carlos Rojas \\ Escuela de Arquitectura, Arte y Diseño \\ Writing lab, Teclabs, Vicerrectoria de \\ Investigacion y Transferencia de \\ Tecnologia \\ Tecnologico de Monterrey \\ Monterrey, Mexico \\ jcrojasl@tec.mx
}

\author{
Juan Luis Higuera Trujillo \\ Institute for Research and Innovation \\ in Bioengieering (i3B) \\ Universitat Politècnica de València \\ Valencia, Spain Escuela de \\ Arquitectura, Arte y Diseño \\ Tecnologico de Monterrey \\ Monterrey, Mexico \\ jlhiguera@i3b.upv.es \\ Javier Marín-Morales \\ Institute for Research and Innovation in \\ Bioengieering (i3B) \\ Universitat Politècnica de València \\ Valencia, Spain \\ jamarmo@i3b.upv.es
}

\author{
Gerardo Muniz \\ Escuela de Arquitectura, Arte y Diseño \\ Tecnologico de Monterrey \\ Monterrey, Mexico \\ gerardo_muniz@tec.mx
}

\begin{abstract}
Design education and practice are continuously
evolving. Educational institutions must include intellectual complexities and new curriculum to support good design education. The design education future emerges multidisciplinary knowledge, teaching innovation and employment necessities. This paper describes a methodology centered in product validation with industrial design students. Focusing on discovering the student experience during the project execution, in addition to observing closely the female design student's perception on the methodology and process developed. The academic project was the design of a novel tool board. The students developed the proposed project in a period of eight weeks. Sixteen students participated as a sample of this research. The methodology consisted of eight phases that spanned from project brief to project conclusion, introducing two phases focused on validation exercises for the elements created to reach the solution of the tool board. During the end of the two evaluation phases, two surveys were applied asking for information on his previous experience during his design education and three elements that assessment the design methodology implementation: utility, novelty, and relevance. Using multiple choice and Likert scale answers the students answered the surveys. The survey's findings revealed relevant information on the project implementation focused on evaluation phases during the product design. The results revealed how students reflected on their previous experience developing projects, and how the design tool board integrate important phases like validation. Also, the students evaluated with a positive value the utility, novelty, and relevance of the developed project. However, the most important finding was the female perception comparing male students. The female assessment of novelty and relevance increased during project implementation, highlighting novelty as a perceived element to a greater range than men. This research results allowed us to discover more information about female students experience with creative and validation processes.
\end{abstract}

Keywords-Design, Educational Innovation, Higher Education, Student attraction, Gender.

\section{INTRODUCTION}

Design practice is continuously evolving; new practice using methods and technologies support disruptive proposal in surrounding areas. Design is widely considered as central element or complement in engineering [1]. However, educational institutions still no include an intellectual complexities and resources on demanded to support good or high design projects [2]. Examples still exist in these days about graduates' students that were perceived by industry and they are being unable to practice their knowledge because the theoretical and practical poorly situated [3]. Nonetheless, the universities must stimulate a triangulation that emerges between knowledge, education, and employment; the higher education must be guided by a perspective of applied research and development aimed to solve problems [4]. In recent decades designers have create ambitious large-scale projects to help and change some aspects in the world [5] and now requited to expand the boundaries in the discipline to include more factors like environmental, social impact and engineering complexities [6].

Nowadays, there is an interest in the intersection between design education and novel design practice. Principally, in the benefits of integrating research for complex solutions. Research and design are now becoming integrated in important parts of design process [7]. Sanders [7] mentions that most design schools are still organized with traditional design practices, but this education practices no longer reflects the needs of a new kind of industry. Consequently, other university departments such as Engineering and Business are now providing courses in design process.

Currently, the design student is required to include convergent or divergent thinking strategies to obtain successful solutions, but both convergent and divergent thinking is necessary thinking skills that can be obtained by teaching similar processes [8]. 


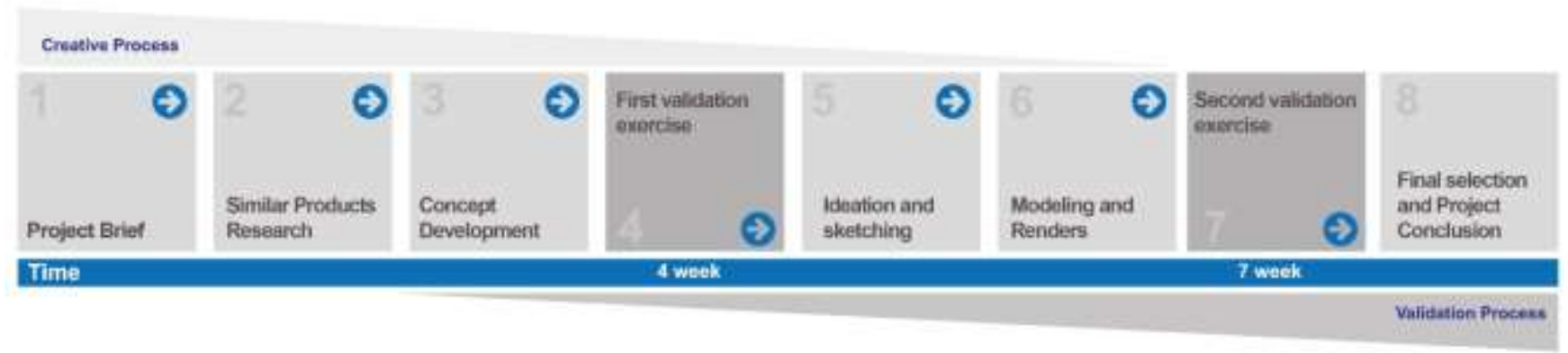

Fig. 1. Design project methodology scheme used in the course.

Alain Findeli [9] proposed a new rethinking of praxis and design education based on extensive research. The author's approach mentioned how science and technology can fit in designer dynamics as a part of creative process including research, for a more effective convergent and divergent solution. Educational institutions must use systems thinking to shift design education for future generations [10], and design education evolution is correlated with engineering education and aspect such as problemsolving methodologies, and creative dimensions, and research [11].

Presently, the research role became relevant aspect of this shift in design industry (e.g., research through design). Also, collaborative competences, communication, a nurturing of new connections among different types of design and stakeholders are the new modern design work [12]. That is why, new design curriculum is focusing on new business development, interactive systems, and user research, include validation dynamics [13]. Weil and Mayfield [13] mentioned that designers are actionoriented and want to impact the world directly, and only they can achieve it if can handle strategic plans, co-development and implementation within trans disciplinary teams that reduce the gap between vision and execution.

In this sense, within the designer's preparation, there are several elements that must be considered for their education. One of the most important is learning styles. The teaching style must adapt for gender, culture, and socio-cultural learning environment; also, own experience plays an important factor in the teaching successful [14]. In this research, our particular interest is to observe the behavior of students by gender. The importance of education lies in the transformation of students' identity [15], motivations and context influence role by students' gender [16]. Motivation is an important element that must be considered. Aspects such as emotions can also be thoughtful; however, it is not the objective of this research. Nevertheless, the design student's motivation is influenced by their gender, meanwhile females are less likely to enjoy certain teaching dynamics, males does, and this affects their performance in design projects [17].

Overall, researchers have demonstrated that males have more positive attitudes for engineering dynamics compared to females. Males appear to be more adapted to technology and numeric exercises [18]. However, exist a gender gap in several aspects that's has nothing to do with the gender of the students [19]. Huffman, Whetten and Huffman [18] assure that female have more strongly attitudes in some specific technology aspect, just have to discover, and tackle them. The relevance of finding of students' motivation in design projects using validation or some other systematic process, is the key to improving their learning process. Laeser et al. [20] exposes that female students who are in their first year are less self-confidence in many engineering courses, after a certain time, these same female students can recognize their abilities and be able to prove it.

With this in mind, one of the important aspects in design are ideas. One particular bias has been prevalent in design students, generally in individual ideas [21]. In particular, also this have been stigmatized by gender, and ownership of ideas is strong in design students. However, designers prefer their own ideas over the other ideas [22], but female students are more collaborative and share the ideas with the collaborative team, meanwhile male students tended to no share and select other ideas [23]. In general, these types of information have important implications for design practices, research, and education. This paper will show how a design methodology that integrates research and validation can positively affect design students, especially female designers.

\section{RESEARCH QUESTIONS}

RQ1: How do students evaluate the utility, novelty and relevance of design methodology using their projects?

RQ2: How methodologies that integrates design and research can impact positively in female students more than male students?

\section{AIM}

The purpose of this research is to describe the designer's opinions when introducing validation dynamics and data use to improve product design. A special attention will be paid to the opinions segmented by the gender of the students and how they compared results obtained using the design project methodology. The result of this research will contribute to a gender perspective and cultural in the discipline.

\section{METHOD}

\section{A. Stuating the case}

Design education is currently suffering a transformation. The Mexico regional context has created a design education creating a bias between engineering and arts complementation. However, students lose knowledge like validation and 
engineering methods. At Tecnológico de Monterrey, several methodological initiatives are being started that integrate technology and validation in design product processes.

\section{B. Design Project Methodology}

The project methodology was created to introduce the elements or aspects design validation into a creative design process. This methodology was replated and improved based a previous research [24], and based on the design thinking model. A popular design method in the discipline and related to product design, in addition to the elements of evaluation and validation [25-28]. The design methodology was divided in eight phases to design a novel tool board. The academic project took eight weeks, approximately 4-5 hours per week. The complete scheme can be seen in Figure 1.

1) Project Brief: Professor presented the challenge to the students. The specifications and limitations were explained, with time and phases execution.

2) Similar Products Research: Students identified various types of tool boards, analyzing their advantages and disadvantages.

3) Concept Development: A creative process was developed based on the relevance of vision, supported by the Gestalt theory. The students developed a series of board archetypes based on geometric silhouettes, contrasting color, and basic shapes.

4) First validation exercise: Validation was developed using 27 board archetypes proposals. The students created an online survey to validate appreciation and understanding of the proposals of people outside the project. Descriptive statistics was used for the validation analyzes.

5) Ideation and sketching: Students decided to make the three best proposals. Details were created, and basic sketching were presented for internal aesthetic validation.

6) Modeling and renders: Students modeled and rendered the proposals in professional programs such as Fusion $360 ®$ and Keyshot $9 \circledR$. The renderings were photorealistic. An example can be seen in image 5 .

7) Second validation exercise: validation of the three proposals was conducted by a new online survey. The students validated the relevance of the proposal regarding the best search times for a tool, and tool board understanding. Descriptive statistics and non-parametric tests were used for the validation analyzes.

8) Final selection and Project Conclusion: Students made a final decision to present one of the tool board according with the best data validation. Students closed the project with a project report with whole phases documented.

\section{Student participants}

This paper utilized information from the Design Products and Systems Two course from the last year of the Industrial Design bachelor's programs. Sixteen students (mean=22.75 years, ds=1.3) divided between 11 women and 5 men completed the course during the Fall-Winter 2020 semester.

\section{Instrument and Methodology Research}

After first and second validation exercises, the students answered a survey which was divided into two type of sections depending the answer: multiple choice and Likert scale. The questions were designed to observe the impact perception of the design progress during the project execution.

Three questions were asked at the beginning of the survey to understand their preliminary students background about and validation processes. The multiple-choice answer were Yes/No/I'm not sure:

1. Do you consider you have practiced a complex product design process in your degree?

2. Do you consider you have practiced an evaluation products process in your degree?

3. Do you consider you have practiced an evaluation process in this board tools design project?

The next question was asked to identify the student's perception about four common phases in a design process.

4. Do you indicate which of the following steps fits with the survey creation and data analysis process?
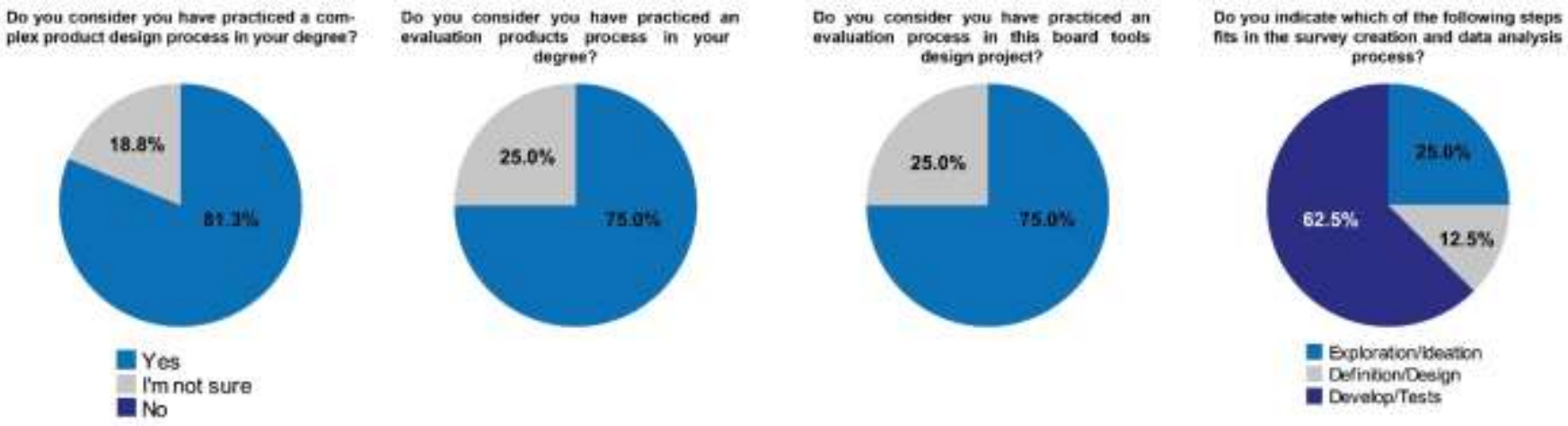

Fig. 2. Percentages for questions regarding students' background for first survey. 


\section{a) Exploration/Ideation, b) Definition/Design c) Develop/Tests, d) Deliver/Feedback}

Finally, the last questions used a 1 to 5 Likert scale, where 5 is the highest rate. The questions were designed to measure the impact of three aspect implicated in the design project methodology.

5. How do you evaluate the utility of the experienced design process?

6. How do you evaluate the novelty of the experienced design process?

7. How do you evaluate the relevance of the experienced design process?

\section{DATA ANALYSIS AND RESUltS}

The data analysis collected by the two surveys was divided in three parts or observations in order to detect the students experience and perception during the project execution. The first analysis examined the opinion comparison of yes/no and the multiple-choice questions. The second analysis calculated the statistical resulted of the Likert scale questions of the first and second surveys. The last results contrast the mean results of the Likert's scale questions.

The first analysis revealed the comparison of the responses from the two surveys. The questions were design to know their background information and how they were perceived the project implementation. The first result can be seen in Figure 2 . They confirmed in the first survey that they have practiced a complex design process $(81.3 \%)$, but an evaluation process was less confirmed $(75.0 \%)$, and after the first validation exercise of the project they considered that during the project, they practiced an evaluation process $(75.0 \%)$. Also, in the last question, students stated that survey creation and data analysis exercise belong mainly to Develop/Test (62.5\%), Exploration/Ideation (25.0\%), and then to Definition/Design (12.5\%) phase process. The seconds result can be seen in Figure 3. For the second survey, students confirmed, after second validation exercise, that their opinions had changed about if they practiced a complex design process, with a yes $(68.8 \%)$, no (6.3\%) and I'm not sure (25.0\%) answers. Also, they confirmed having made an evaluation process at the end of the project, with yes $(81.5 \%)$, no $(6.3 \%)$, and I'm not sure (12.55) answers. Further, after second validation exercise of the project, they considered have been practiced an evaluation process $(81.3 \%)$. Finally, in the last question, the student stated that survey creation and data analysis belong to the Develop/Test (68.8\%), Exploration/Ideation (18.8\%) and Definition/Design (12.5\%) phase process.

The second analysis revealed the findings from the Likert scale answers. The elements evaluated were answered as follows: Means results obtained by the first survey were utility (mean=4.25), novelty (mean=3.56) and relevance $($ mean=3.94), where utility was the best valued. Focused on the comparison by gender, the female students emphasize their assessment of novelty $\left(\right.$ mean $\left._{\text {female }}=3.73\right)$ more than the male students $\left(\right.$ mean $\left._{\text {male }}=3.20\right)$. The other elements male students have a better assessment. The results obtained by second survey at closing the project were utility (mean=4.31), novelty (mean=4.25) and relevance $($ mean $=4.25)$, where novelty and relevance were the best valued. Focused on the comparison by gender, the female students repeated their assessment of novelty $\left(\operatorname{mean}_{\text {female }}=4.36\right)$ with a better value of male students $\left(\operatorname{mean}_{\text {male }}=3.20\right)$. Also, the other elements male students have a better assessment. The complete descriptive statistics are show in Table 1 and Figure 4.

The last analysis requires a Statistical analysis using SPSS 17.0 for Windows ${ }^{\mathrm{TM}}$ (IBM SPSS Inc., Chicago, IL, USA). A noparametric test (Wilcoxon) was applied to examine the comparison between the element's perception during the project execution. A complete table of data is presented in Table 1. The test revealed one of three variables present a significant value $(p<0.05)$. In the question "How do you evaluate the novelty of the experienced design process?" showed a significant value $(p=0.009)$.

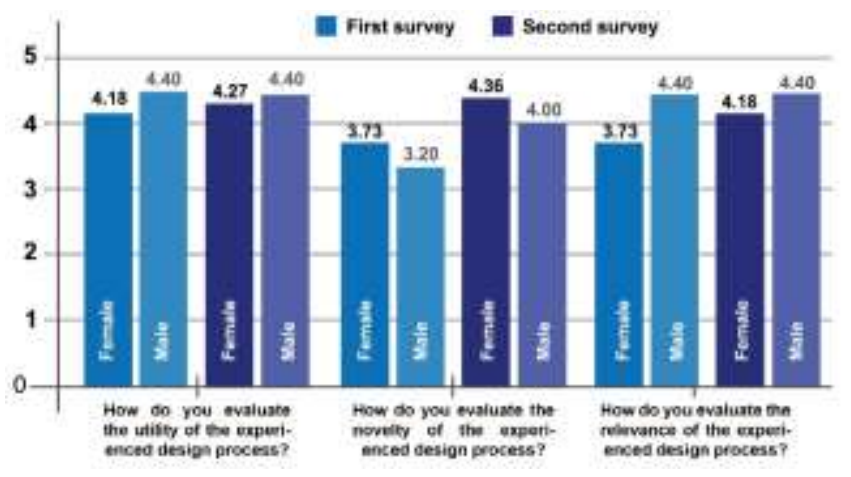

Fig. 4. Means of utility, novelty and relevance by gender. 
Do you cansider you have practiced a cent. plex product design process in your degree?

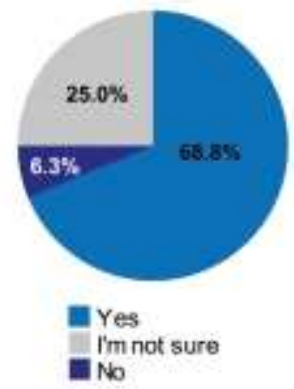

Do you consider you have practiced an evaluation products procenss in your

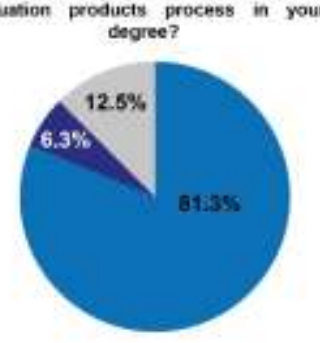

De you consides you have practiced an evaluation process in this bourd tools

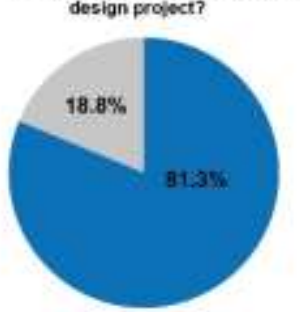

Do you indicate which of the folfowing steps fits in the survey creation and data analysis

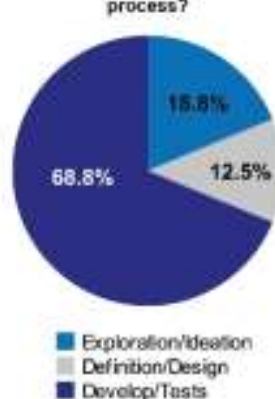

Fig. 3. Percentages for questions regarding students' background for second survey.

\section{DISCUSSION}

This research is added part of a series of observations focused on impact of design methodologies and validation processes in design products. This paper emphasis the experience and perception of a design students' group during a develop of a tool board. Based on the result of this papers, we can answer our two research questions. Firstly, our observation reveled how student's perception let clear the based state at the beginning of the project. The students recognize not having practiced a complex design process. During project execution, the affirmative answer decreased by $12,5 \%$, revealing that the project provided a point of comparison. On the other hand, the students recognize having practiced an evaluation product process, the affirmative answer increasing by $6.3 \%$, and supported by the same effect in the question about the evaluation process in this design project (increasing by 6.3\%). Finally, Finally, the students reaffirmed their understanding of the "Develop/Test" phase during the development of the project, increasing between surveys by $6.3 \%$.

The second part of the survey revealed how students perceived the utility, novelty, and relevance aspects of this design methodology implementation. With this information, we can focus on answering the RQ1: How do students evaluate the utility, novelty and relevance of design methodology using their projects? The three aspects were evaluated in the two surveys, observing a positive increase from the first to the second survey. The students showed that they had a positive experience mainly with the novelty and relevant aspects, marked a tendency to observe in gender segmentation. Then, with the result of the segmentation of the valuation of women and men, we can answer RQ2: How methodologies that integrates design and research can impact positively in female students more than male students? The female students perceived in a significant means the novelty of the project's design methodology, where it was more marked even among male students. Also, the relevance experienced, where male students there was no change. Lastly, but not significant is the increase in utility, however, even male students did not show a change.

This research reveals important information about the experience that female students have in a design project, integrating evaluation elements such as surveys, databases, and basic statistical analysis. Under the same educational formation and cultural elements of the students, in male students there is no increased effect seen with female students. This opens the discussion to understand female students can experiencing a novel process using creative and validation/evaluation methods. Agreeing with many the literature described, where the relevance of the type of project $[16,17,18,19]$ can break paradigms in design education, and female students can develop and deliver a design project with these characteristics [18, 20]. The project experience during class, yielded information by mixed teams dynamics observation, where ideas development and tracing of

TABLE 1. Descriptive Stadistics and Wilcoxon Test.

\begin{tabular}{|c|c|c|c|c|c|c|c|}
\hline \multirow{2}{*}{ Questions? } & & \multicolumn{2}{|c|}{ First survey } & \multicolumn{2}{|c|}{ Second survey } & \multirow{2}{*}{$\underset{\text { (wilcoxon) }}{\mathbf{Z}}$} & \multirow{2}{*}{$\begin{array}{l}\text { Aysmp. Sig } \\
\text { (2-tailed) }\end{array}$} \\
\hline & & Mean & Std. Dev & Mean & Std. Dev & & \\
\hline \multirow{3}{*}{$\begin{array}{l}\text { How do you evaluate the } \\
\text { utility of the experienced } \\
\text { design process? }\end{array}$} & Total & 4.25 & 0.775 & 4.31 & 0.793 & \multirow{3}{*}{$-0.577^{a}$} & \multirow{3}{*}{0.564} \\
\hline & Female & 4.18 & 0.751 & 4.27 & 0.786 & & \\
\hline & Male & 4.40 & 0.894 & 4.40 & 0.894 & & \\
\hline \multirow{3}{*}{$\begin{array}{l}\text { How do you evaluate the } \\
\text { novelty of the experienced } \\
\text { design process? }\end{array}$} & Total & 3.56 & 1.094 & 4.25 & 0.775 & \multirow{3}{*}{$-2.598^{a}$} & \multirow{3}{*}{0.009} \\
\hline & Female & 3.73 & 0.786 & 4.36 & 0.674 & & \\
\hline & Male & 3.20 & 1.643 & 4.00 & 1.000 & & \\
\hline \multirow{3}{*}{$\begin{array}{l}\text { How do you evaluate the } \\
\text { relevance of the experi- } \\
\text { enced design process? }\end{array}$} & Total & 3.94 & 1.063 & 4.25 & 0.856 & \multirow{3}{*}{$-1.633^{a}$} & \multirow{3}{*}{0.102} \\
\hline & Female & 3.73 & 1.104 & 4.18 & 0.874 & & \\
\hline & Male & 4.40 & 0.894 & 4.40 & 0.894 & & \\
\hline
\end{tabular}




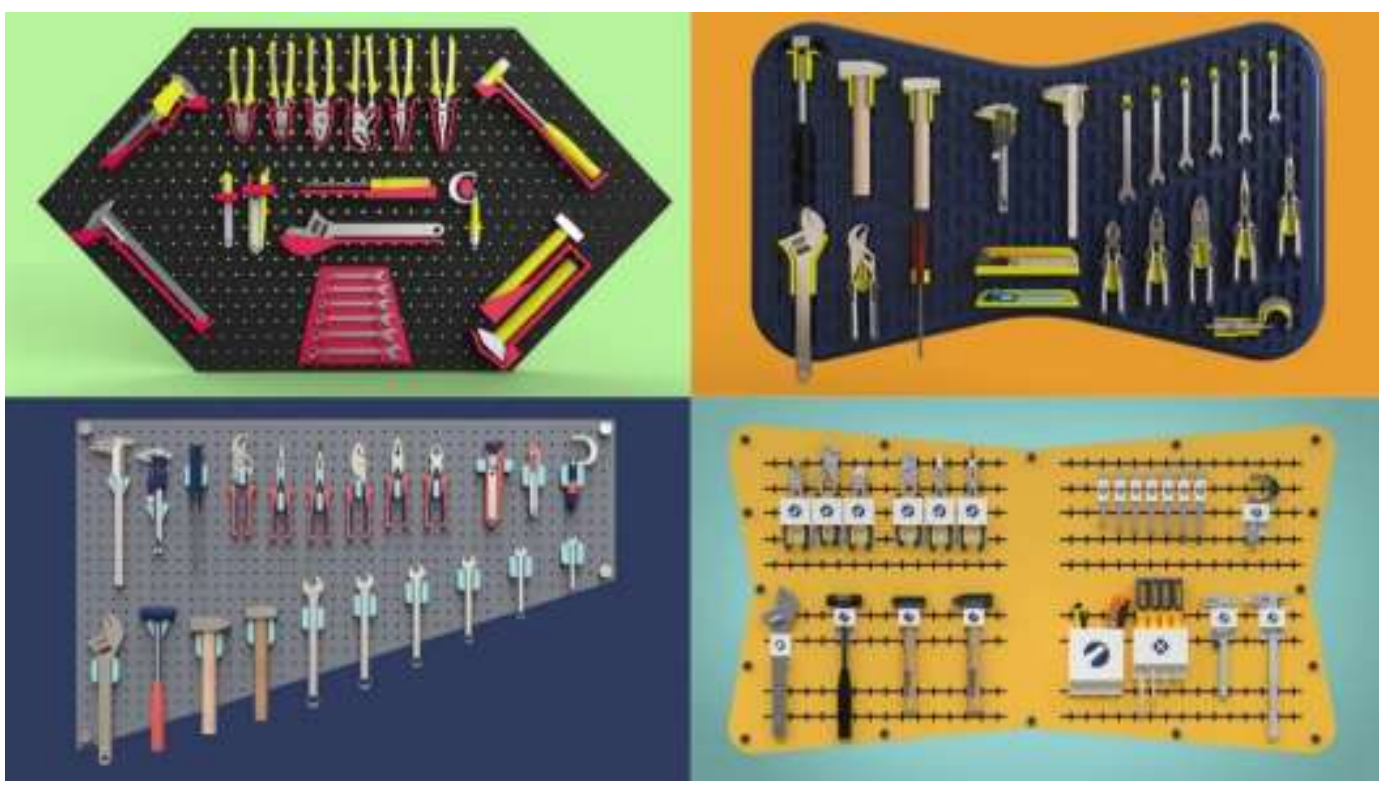

Fig. 5. Example of tool board project develop during the course.

the methodology was not a limitation, including the motivation of female and male students for designing an aesthetic and functional tool board.

\section{CONCLUSION}

This research results allowed us to learn more about the product validation perception on creative processes. The tool board design was a project that allowed female and male design students to experience a dynamic that required the use of more technical tools. This research continues to increase the interest in tracing students' performance in innovative teaching dynamics, contributing to the paradigm shift of current design education. This work was limited by the sample of students, but the same design methodology will continue to be applied to increase the number of cases and courses. Finally, one more learning from this research is how design students are able to solve problems without leaving aside the aesthetic elements of the designer's formation.

\section{ACKNOWLEDGMENT}

The authors would also like to acknowledge the financial support provided by the NOVUS grant ID: N20-158-41 (Validación científica como herramienta educativa en proyectos de carácter creativo), as well as the support of the Writing Lab and TecLabs at Tecnologico de Monterrey, Mexico, throughout the production of this work.

\section{REFERENCES}

[1] H. A. Simon, The Sciences of the Artificial, 3rd ed., Cambridge, Mass.s: MIT Press, 1996.

[2] R. H. Todd, and S. P. Magleby, "Evaluation and Rewards for Faculty Involved in Engineering Design Education," International Journal of Engineering Education, vol. 20, No. 3 (2004): pp. 333-340.

[3] A. J. Dutson, R. H. Todd, S. P. Magleby, and C. D. Sorensen, "A Review of Literature on Teaching Design Through Project-Oriented Capstone Courses," Journal of Engineering Education, vol. 76, No. 1 (1997): pp. 17-28.

[4] D. Matos, M. Terroso, and J. Sampaio, “The Growing Path in Search of an Industrial Design Identity,” Procedia CIRP, vol.84 (2019): pp. $353-356$.

[5] T. P. Hughes, Rescuing Prometheus: Four Monumental Projects that Changed the Modern World, New York, N.Y: Random House, 1998.

[6] D. Hastings, "The Future of Engineering Systems: Development of Engineering Leaders," Engineering Systems Symposium, Cambridge, Mass., 2004.

[7] E. B. N. Sanders, "Design Research at the Crossroads of Education and Practice," She Ji: The Journal of Design, Economics, and Innovation, Vol. 3, No.1 (2017): pp. 3-15.

[8] A. Shettar, M. Vijaylakshmi, and P. Tewari, "Categorizing student as a Convergent and Divergent Thinker in Problem-solving using Learning Analytics Framework," Procedia Computer Science, Vol. 172 (2020): pp. 3-8.

[9] A. Findeli, "Rethinking Design Education for the 21st Century: Theoretical, Methodological, and Ethical Discussion," Design Issues, vol. 17 (2001): pp. 5-17.

[10] B. H. Banathy, "Systems thinking in higher education: learning comes to focus," Systems Research and Behavioral Science, vol.16, No. 2 (1999): pp.133.

[11] L. Trevisan, P. P. Peruccio, and S. Barbero, "From engineering to industrial design: issues of educating future engineers to systemic design," Procedia CIRP, vol. 70 (2018): pp.319-324.

[12] E. Voûte, P. J. Stappers, E. Giaccardi, S. Mooij, and A. Van Boeijen, "Innovating a Large Design Education Program at a University of Technology," She Ji: The Journal of Design, Economics, and Innovation, vol. 6, No.1 (2020): pp. 50-66.

[13] D. Weil, and M. Mayfield, "Tomorrow's Critical Design Competencies: Building a Course System for 21st Century Designers, "She Ji: The Journal of Design, Economics, and Innovation, vol. 6, No.2 (2020): pp. 157-169.

[14] A. Datta, "Gender and Learning in the Design Studio," Journal for Education in the Built Environment, vol. 2, No.2 (2007): pp. 21-35.

[15] R. K. Ruedi, "Bauhaus Hausfraus: Gender formation in design education, “Journal of Architectural Education, vol.55, No.2 (2001): pp. 73-80.

[16] A. Phakiti, “A closer look at gender and strategy use in L2 learning. Language and Learning,” vol. 53, No.4 (2003): pp. 649-702. 
[17] O. O. Demirbas, and H. Demirkan, "Learning styles of design students and the relationship of academic performance and gender in design education," vol. 17, no.3 (2007): pp. 345-359.

[18] A. H. Huffman, J. Whetten, and W. H. Huffman, "Using technology in higher education: The influence of gender roles on technology self-efficacy," Computers in Human Behavior, vol. 29, No.4 (2013): pp. 1779-1786.

[19] J. Cooper, "The digital divide:The special case of gender," Journal of Computer Assisted Learning, vol. 22 (2006): pp. $320-334$.

[20] M. Laeser, B. M. Moskal, R. Knecht, and D. Lasich, "Engineering Design: Examining the Impact of Gender and the Team's Gender Composition," Journal of Engineering Education, vol. 92, No.1 (2003): pp. 49-56.

[21] S. Y. Cooper, and W. A. Lucas, "Developing Self-Efficacy for Innovation and Entrepreneurship: An Educational Approach," International Journal of Entrepreneurship Education, vol. 4 (2006): pp. 141-162.

[22] B. Onarheim, and B. T. Christensen, "Distributed Idea Screening in Stage-Gate Development Processes,” Journal of Engineering Design, vol. 23 , No.9 (2012): pp. 660-673.

[23] C. A. Toh, A. A. Strohmetz, and S. R. Miller, "The Effects of Gender and Idea Goodness on Ownership Bias in Engineering Design Education," ASME. J. Mech. Des. vol.138 (10), August 30, 2016, pp.

[24] J. C. Rojas, J. C. M. Cañizares, J. L. Higuera-Trujillo, and G. Muniz, "An Eye-Tracking Project in Industrial Design Education: A case study for Engaging in the Research Process," 2020 IEEE Global Engineering Education Conference (EDUCON), Porto, Portugal, 2020, pp. 127-132.

[25] J. Blizzard, L. Klotz, G. Potvin, Z. Hazari, J. Cribbs, and A. Godwin, "Using survey questions to identify and learn more about those who exhibit design thinking traits," Design Studies, vol. 38 (2015): pp.92-110.

[26] M. Borge, D. Toprani, S. Yan, and Y. Xia, "Embedded design: Engaging students as active participants in the learning of human-centered design practices," Computer Science Education, vol. 30 (2019).

[27] Y. Li, A. Schoenfeld, A. Disessa, A. Graesser, L. Benson, L. English, and R. Duschl, (2019). "Design and Design Thinking in STEM Education,” Journal for STEM Education Research. vol. 2 (2019): pp. 93-104.

[28] T. K. F, Chiu, P. J. Williams, C. Chai, T-J, Lin, (2021). "Teacher Professional Development on Self-Determination Theory-Based Design Thinking in STEM Education,” Educational Technology \& Society, (2021): pp. 1176-3647. 